\title{
Our Gifted Children: Are They Asking Too Much?
}

(keynote address to National Association for Gifted Children, November 6, 1993) Stephanie Pace Marshall

Thank you, and good morning. It is indeed a pleasure and a privilege to be with you during your annual conference as you focus on the development of connections, linkages, and partnerships of all kinds to further the development of talent; and I am particularly energized to be with you at this time when the work that we are doing as educators of and for gifted and talented children is once again viewed as essential to our nation's future.

The primary focus of my remarks is the development and nurturance of intellectual and creative talent. I will use as a framework the development of talent in mathematics and science and the institution I know best - the Illinois Mathematics and Science Academy - the nation's first, and to date only, 3-year public residential high school for students highly talented in mathematics and science. Despite the specificity of this learning environment, I hope you will transcend its context and apply the principles and critical attributes l'm describing to the creation of any learning community designed to develop and nurture talent.

The title of my remarks is: "Our Gifted Children: Are They Asking Too Much?" It is within this context that I want to talk about the development of talent through the creation of learning communities that foster intellectual rigor, creativity, curiosity, and risk. Before I do so, however, I want to create a national context through which you can view my remarks and within which you can place our concern for the development of talent in America. As we review gifted education and as we examine the educational continuum from pre-kindergarten through postsecondary education, it is critical, in this new era of educational reform in which gifted education is still a contentious topic, that we place the education of this specific population of America's children within the framework of our nation's current educational commitment.

Albert Einstein once said that one of man's greatest problems was the clarity of means but a confusion of ends; a propensity to separate the wheat from the chaff and then throw away the wheat. While I believe many educators in our nation are encouraged by the leadership talent in the Education Department, I am concerned that the Federal government's legitimate long-term and strategic role to establish frameworks for national outcomes and standards of accountability could be eroded by a propensity of the American public to demand and embrace short-term, quick-fix, non-systemic strategies to achieve them. We cannot allow ourselves to be seduced into debating only issues of means -- it deflects our resources and our attention - rather we must focus on ends, the primary of what we must do, and that is to build capacity by increasing student learning, achievement, and competency for all students in America. Presently 
we are confused because we do not yet have a coherent structure to guide and give leadership to the nation. And without a sustained commitment to infrastructure reforming and the integration of all interdependent and dynamic dimensions of our educational system, authentic change will be an illusion.

Our nation is now at a crossroads in education, and it will take more than the reform of schools to improve it. It will require a refocusing of the national will, a belief that all children can learn, and a bold commitment to rewrite the present social covenant that now says it is okay to have a bifurcated system of have's and have not's in America's schools. Unfortunately, we see this bifurcation in subtle but profound ways when it comes to the identification and nurturance of talent in minority children. Within this framework of our commitment to enhance learning opportunities for all students, what is being conveyed to us as educators committed to developing the talents of gifted youngsters?

Ironically and sadly when the world is crying out for enlightened leaders, there is now increased ambivalence and often discomfort in our nation's commitment to develop and provide for the unique needs and talents of gifted students. Due to increased competition for diminishing financial resources and increased questioning of the wisdom and efficacy of specialized programs, public discussions have often focused on the reduction or elimination of programs that identify and challenge our most talented students. While enhancing the proficiency and competency of all of America's children is our obligation and their right, we know it is both naïve and erroneous to believe the pervasive conventional wisdom that says that gifted kids will make it on their own because the "cream always rises to the top."

It has been documented over and over again that in order for talented children to realize their contributions to self and society, they require educational opportunities to self and society. They require educational opportunities and experiences not ordinarily provided in school programs (Markland, 1972). Benjamin Bloom, in a seminal work entitled, Developing Talent in Young People (1985), studied 120 immensely talented individuals, and he found "strong evidence that no matter what the initial characteristics (or gifts) of the individuals, unless there is a long and intensive process of encouragement, nurturance, education and training, the individuals will not attain extreme levels of capability..." (p. 3). This is the "quiet risk" in the education of gifted youngsters. And so it is within this context that I ask the question again: Are our gifted children asking too much?

Although my comments will focus on the learning experiences necessary to develop talent primarily in mathematics and science, I am proposing a framework for the creation of any learning community that will facilitate the development and nurturance of talent in multiple disciplines and in multiple intelligences. In an article called, "The Other Crisis in American Education" in the 
November 1991 issue of Atlantic Monthly, Daniel Singal discusses what he calls the "functional disability" of many of our nation's brightest youngsters. According to Singal, "We tend to assume that with their high aptitude for learning, they should be able to fend for themselves. However, the experience of the past 15 years has proved decisively that they can't' (p. 59).

Although gifted students consistently graduate with presumed disciplinary mastery, there is mounting evidence to suggest that they also graduate with thinking characterized by stereotypes, misconceptions, unexamined assumptions, and rigidly held algorithms that do not enable them to achieve genuine understanding. Our task, then, as educators of the gifted, is to ensure that we create communities that enable our students to experience greater rigor, coherence, and complexity in what they are learning; to increase their intellectual interaction with faculty and fellow students; and to foster collaborative and dynamic approaches to learning that enable students to forge interdisciplinary connections and develop integrative ways of knowing. We must create a learning culture and ethos that provides a forum to risk and to experiment and that redirects the learning experience toward greater intellectual, social, and emotional engagement.

A colleague of mine in Scotland, Dr. Cameron Harrison, frames our quest in an interesting way when he says: "I have formed the view that whatever the ultimate source of exceptional performance, it is the result of exceptional learning." Therefore, says Harrison, "I prefer to address the question - how can we best produce exceptional learning?"

Over the last 8 years, the Illinois Mathematics and Science Academy has been authentically wrestling with this question of how to create an environment for exceptional learning. With our nation's keen interest in mathematics and science, the Academy could have taken the easy road and developed a rigorous program in mathematics and science which only fostered discipline-specific knowledge acquisition and acceleration, where the arts and the humanities were second-class citizens and where interconnections and interdisciplinary learning were not explicitly fostered. But we did not. Although our purpose is to transform teaching and learning in mathematics and science, the means by which we have chosen to do so is by developing ethical leaders who understand the joy of discovering and forging connections within and among mathematics, science, the arts, and the humanities.

The Illinois Mathematics and Science Academy is committed to establishing a learning environment in which talented students are broadened in their response to the beauty of ideas, to relationships, to patterns, to structures, and to natural symmetries. Our mission directs us to develop leaders who: (a) understand that knowledge is not segmented or separated disciplines, (b) have 
distinctive and integrative ways of knowing, (c) have the habits of mind and heart that lead to holistic insight and comprehension.

For that reason, the Academy's curriculum focuses on critical and creative problem-finding and resolution with four primary goals:

1. To develop intellectual potential, academic achievement, creativity, and responsibility in all students.

2. To approach mathematics and science as the products of human creativity and curiosity.

3. To foster interdisciplinary approaches to thinking and learning by integrating the study of mathematics and the natural and social sciences with the arts and the humanities.

4. To practice what we are calling "apprentice investigation" appropriate to each discipline.

The primary focus of our program is on the development of students as inquirers and apprentice investigators, and while much of our instruction occurs in classrooms or laboratories, our unique residential environment promotes learning far beyond the classroom and the typical day.

Our curriculum is designed to promote what we are calling standards of significant learning which represent and provide evidence for the habits of mind that contribute to integrative ways of knowing, and we expect these ways of knowing to broaden and deepen over time. We are still in the process of defining these standards and what they "look like" within various learning experiences and how they can be assessed, but several are enumerated below.

1. Construct questions which further understanding, forge connections, and deepen meaning.

2. Pursue and explore connections between areas of knowledge.

3. Identify and characterize the composing elements of structures and systems.

4. Recreate the "beautiful conceptions" central to literacy in mathematics, science, fine arts, and the humanities.

We are at a point in the development of our learning community where we have the opportunity truly to shape the context of student learning, to shape the way students' view mathematics and science, and to shape the context within which they perceive mathematics and science as essential tools for solving the problems that plague us as a world society.

Mathematics is a language of connection, patterns, and symmetry, but it has been viewed as linear and discrete. Within the framework of exploration and discovery in mathematics and science our students must be enabled to view 
these disciplines as languages and as forms of literacy whose knowledge base, values, symbol systems, metaphors, and concepts can enhance and enrich the understanding of other disciplines and other forms of knowing. Gifted students must become multilingual; they must be able to translate and use the symbol systems of one discipline to understand the complexities of others.

Given this commitment to teach our students the symbols, metaphors, and language of the discipline, we have developed an integrative learning system that facilitates the development of what we are calling decidedly different learners, learners who are prepared to face the challenges of the $21^{\text {st }}$ century with knowledge, analytical and evaluative skills, and ethics. We want our young learners to think creatively and innovatively. We want them not to be afraid to use imagination and intuition in the generation and solution of problems, and we want them to experience the joy and excitement of learning.

Let me give you a simple illustration of the excitement of learning we are striving to cultivate. I received this sample of student work from a social science teacher who has, for the last several years, asked his students to keep what he termed a Thinking Log. This is an excerpt from a sophomore student's log.

\section{LOVE THIS PLACE!}

This is the strangest place l've ever been. It is the only lace I know where people can sit around at lunch and argue honestly about the velocity of a falling blob of ketchup. (Yes, that really happened. I was arguing as well, but my point was from how high you dropped the ketchup). I think that this is the only place where people can sit around and discuss physics and feel NORMAL while doing so.

.... as soon as sophomores arrive here, IMSA begins to affect them. I know it is affecting me. People I know have observed this changing and have told me about it.

[For] example: Last night my roommate was drinking soda from a glass cup and for some reason all the foam stayed at the top so that while the liquid went down in the glass, the foam remained up so that there were gases in between.

[Then she drew an illustration.]

She shouted, "Hey, look!" We all rushed over and stared at her soda for a few minutes. Then we tried to figure out why it did that. Finally, one of my roommates grabbed a camera and took a picture of it for our photography class. It was really an interesting occurrence. 
I love this place!

As you can see, our commitment goes far beyond intellectual development!

As leaders of the next generation, we want to make sure our students have healthy and positive self-concepts and that they leave our institution with a sense of social awareness, an ability to make decisions within a moral and ethical framework, and an understanding that they have a responsibility to work toward the improvement of the public good through their ability to solve the technological and social problems facing our world. Our commitment to integrative ways of knowing is pervasive and it provides both the contextual scaffold and the screen through which our program is evaluated.

The reason this is so critical is that integrated ways of knowing can only be nurtured in a learning environment that fosters what a member of our English faculty has called the "interrogative mood."

If we are to develop ways to make active student discovery happen, take hold, and endure, we must define who we are in the classroom. A teacher who facilitates discovery, who creates the environment that makes discovery possible must realize that there is not an environment out there for them, the students, but that the interrogative mood includes the teacher as well.

It is not enough to ask questions that evoke responses. One could do that all day and cover nothing but fact. The teacher must raise questions that genuinely puzzle the asker.

Facilitating discovery is the ultimate intellectual exposure because the way to encourage thinking is to be thinking yourself. (Michael Casey)

In facilitating discovering in mathematics and science, we must model the very essence of scientific inquiry.

Unfortunately, this commitment to collaboration and inquiry is too often omitted in gifted programs that emphasize only information accumulation and content mastery. It is no secret that it is possible to get an 800 on the SATM and a 5 on an AP physics exam and still not authentically understand basic concepts of the physical world. Because the context of knowledge acquisition defines the way we learn things, the educational process in our country needs to be transformed to promote active engagement in learning. We need to move away 
from schooling to learning; and we need to move away from isolated classrooms and unconnected schools to the creation of learning communities. It is imperative that we not only provide opportunities for authentic inquiry, but also immerse the student in an environment where she can learn and demonstrate skills for sensing and finding problems, for constructing arguments, and for scaffolding complicated performances.

An example of an interdisciplinary course at the Academy, taught by a physics and social science instructor, that enables what l've just described is Science, Society, and the Future, and it utilizes an instructional pedagogical technique called problem-based learning that originated in medical schools. In this course of study, designed by Academy staff Bill Stepien, David Workman, and Shelagh Gallagher, students are confronted with ethical questions and the implications inherent in making public policy decisions about controversial scientific issues, such as electromagnetic fields, fetal research, and nuclear waste. Armed with only minimal information on an issue or problem, students are asked to investigate data and determine whether or not a problem exists. Then they generate questions, conduct research, analyze data, formulate policy options, choose and defend the posed solutions, anticipate implications and consequences for society, and design controls accordingly. Confronting students with ill-defined, ill-structured, and "messy" problems, the kinds presented in the real world, is the essence of this course and the Academy's program.

In addition to curricular changes, our teaching strategies are also being modified. Teachers are designing classrooms to facilitate discovery and construct meaning rather than merely impart information. Like their students, teachers are taking risks and experimenting - not always knowing the outcome or answer in advance. The rationale for doing this is simple: Integrated learning and interdisciplinary teaching promote creative and critical thought. The Academy has consciously chosen to emphasize mathematics and science within the framework of an integrated and holistic view of learning. To measure student achievement, we look at what students are actually doing - in and out of the classroom. We assess student exhibitions, videotape presentations, lab experiments, and research projects compiled in portfolios so that we can see demonstrated evidence of students' ability to think independently, conduct research, communicate, analyze and synthesize data, and solve complex problems.

One of the strategies the Academy has developed for assessing our students' ability to discover and forge connections is an instructional tool called The Thinking Log, a cognitive diary of ideas, concepts, and questions in which students record their thinking about their own thinking. Let me share one of the Thinking Logs prepared by a sophomore female student which illustrates the power of interdisciplinary, integrative thought to promote conceptual understanding. 
In school today, in English class, second hour, I thought of something. Socrates and special relativity have a lot in common. For Socrates, different perceptions may produce different truths or realities. In special relativity, the velocity of an object is relative to the observer - it changes.

For Socrates, there is no true reality. In special relativity, there is no real velocity.

For Socrates, God's reality is the only real one, but we can never really know it. In special relativity, the speed of light is the ultimate reality, but we can never really reach it.

For Socrates, each point of view, each, reality is valid if it can withstand interrogation. For special relativity, each different velocity is valid if it is congruent with the equation for velocity.

I don't know if the way I worded these comparisons makes a whole lot of sense, but it was perfectly clear to me in English today.

In addition, Socrates says not to give blind respect and judgment to people and things. The unexamined life is not worth living, he said. So, if you don't understand and examine questions, it's pointless.

What good are they if you don't know where they came from, or why they work?

This entry in the Thinking Log illustrates the power of being able to use multiple symbol systems to unlock concepts. Understanding the complexity of special relativity was dramatically enhanced by understanding Socrates. And understanding the nuances of Socrates was enriched by special relativity.

I am not a physicist; however, because I live in a scientific institution, science has become a far more significant part of y life. In an effort to understand how organizations work and function optimally, I have found myself talking with several members of our science team (chemistry, biology, physics) and asking them to teach me about physical, chemical, and biological systems. Our discussions led naturally to my reading about chaos theory, self-organizing systems, fractals, and most recently, complexity theory.

I must say that I am overwhelmed by what I am reading and coming to understand. While we have been using the tools of our current conceptual 
frameworks about teaching and learning and how the world works, and while we have been working so hard to design complex structures, processes, and systems that we thought would enhance learning and creative capacity, a revolution has been occurring in science, an enormously profound paradigm change that is going to alter forever the way we view and make sense of the universe and, hence, the way we structure our institutions, including our schools. And I believe this new understanding of the universe can also profoundly change the paths we either design or allow to emerge that will cause us to liberate human creativity and lead to the creation of the authentic learning communities that we have been talking about. In short, a new physics for a new social order is emerging.

We are now beginning to understand that beyond the mechanistic and deterministic universe of Sir Isaac Newton, who gave us classical physics, gravitation, the laws of mechanics, and the image of a repetitive, predictable, linear, and clockwork universe, the new physics, especially at the subatomic level, is opening up new ways of comprehending the universe. This new science is grounded in relational holism, patterns, self-organizing and self-renewing systems, networks, connections, and generative information. The metaphor for the Newtonian universe is a clock; the metaphor for the nonlinear universe is a kaleidoscope.

Sadly, we have designed schools and institutions of learning characterized by the following: constrained creativity and opportunity, untapped resources and diminished curiosity, and stifled imagination.

Furthermore, we currently have a paradigm of learning that says that education is passive and incremental, not dynamic and developmental; learning is dispensed information, not constructed meaning; potential and capability are bounded, not capable of being enhanced; learning is defined by the calendar and not performance; teaching can be segregated into discrete domains; coverage and reproduction are more important than understanding and meaning; rote memory is better than spatial memory; prior knowledge is unimportant; content segmentation is more highly valued than concept integration; evaluation can only be subjective and external, not qualitative and self-corrective; competition is a far more powerful motivator than cooperation; and what Rex brown calls the "primary conditions of thoughtfulness, [which include] mystery, uncertainty, disagreement, important questions, ambiguity, curiosity" (1991, p. 234) are thought to be soft and lacking in rigor.

What all this means is that we must completely transform the paradigm of schooling and learning as we know it and change our schools into the kaleidoscopic learning communities we have been talking about. We must ground our educational restructuring in the science of our times. For years we have been trying to fix the parts, fix the curriculum, fix the schedule, fix the kids, 
fix the tests; I think now we are beginning to realize that we must change the way we think. We must create a new way of seeing and being in the world and this will obviously cause us to change what we do, a change which, in my view, has profound implications for the education of the gifted.

Changing our habits of mind and heart will enable us to create a more integrative, holistic, and systemic vision of the world which will flow naturally into a new vision of a learning community - a community that enables students to find greater intellectual and social coherence in what they learn; that enables them to interact freely with information of all kinds - collaborating with faculty, staff, students, and others; and that fosters interconnections and integration.

In my view, this is precisely the kind of educational program and environment that must be created for gifted youngsters. This is the kind of long and intensive process of education that our gifted youngsters must be exposed to and nurtured in if they are going to attain extreme levels of capability. The school environment must foster the use and transference of multiple symbol systems. We must not teach each discipline as if it were an arbitrary division unconnected to anything else; we must demonstrate the application and relevance of one discipline to another, or we will create learning disabled youngsters who do not have the tools to understand the complexities and interconnections among knowledge and who are not fluent enough to choose the symbol systems appropriate to solve the problem.

When President Kennedy challenged NASA to have a man on the moon, the NASA scientists cold literally go outside and look into the heavens and see the moon. Their task was to develop the delivery system and the technology that would get us there. But in a very real sense, the task of educators is not that simple... we must invent the moon. We must say to ourselves, what does a learning environment look like that will allow gifted students to become scholars, researchers, and investigators? What would a school and a learning environment look like that would enable talented students to become independent and thoughtful learners? What kind of educational delivery system would we have to develop that would promote social awareness and responsibility among our academic leaders that would enable gifted youngsters to make decisions within a moral and ethical context, and that would foster interdisciplinary approaches to thinking and learning? Quite frankly, we are going to have to do a great deal of experimentation, and we are going to have to develop it by working together. The dialog will be intense and unsettling.

It is true that schools like the Illinois Mathematics and Science Academy are unique environments that can more easily differentiate instruction for extraordinary young people because we seek students with a crystallized set of abilities. The critical issue, however, is not the magnet school, but any program that is designed to foster intellectual behavior, curiosity, problem solving, inquiry, 
creativity, and discovering and forging interconnections to enhance constructed meaning. The Illinois Mathematics and Science Academy is a special learning environment for many reasons - not the least of which is the extraordinary talent of our students and staff.

However, the commitment that differentiates us from other specialized schools for students gifted in mathematics and science is the recognition that the leaders of the $21^{\text {st }}$ century must be able to discover and forge connections among and within mathematics, science, the arts, and the humanities. They must be able to frame their intellectual responses within the context of human values, and they must realize that like the arts and the humanities, science and mathematics are also languages of relationship and symmetry.

The title of my remarks was "Our Gifted Children: Are They Asking Too Much?" I assume by now you have answered this question for yourself, but allow me to answer it as well by returning to the Thinking Log of the young woman who described the relationships between Socrates and special relativity.

I wish I could still draw. When I was in grammar school I used to draw pretty decently. I love to draw in pencil and chalk. Art of all kinds intrigues me, but I also love music and painting, and carpentry and metal working, and dancing, and sewing and embroidery, and cooking.

I want to dance in my old ballet class, play my clarinet, draw thousands of pictures, create beautiful poems and pieces of woodwork, cook and sew for my children, decorate my home, have a good marriage, be an active volunteer, go to church, be an astrophysicist, go to Mars, and understand all my questions about life.

That's not too much to ask, is it?

I hope you would all respond to this young woman. "No, that is not too much to ask."

What troubles me, however, is that we must not only be aware of how to create the environment that enables gifted youngsters to ask all these questions but also create the environment in which it is safe for them to test their answers at various stages of their intellectual development. Our gifted children are asking us to develop a learning community that fosters intellectual meaning and understanding and that provides time for authentic learning and reflection. Howard Gardner, in his book, The Unschooled Mind: How Children Think and How Schools Should Teach (1991), proposes that two of the best structures for learning are museums and apprenticeships. Think about that for a moment. 
What is it about a museum that captures a child's fantasy and imagination and engages her in genuine discovery? What is it about the apprenticeship relationship that enables one safely to acquire and practice new learning and new skills?

The responses you may be thinking about are likely to be varied, but let me suggest why I think these structures are so powerful for learning. It is because they facilitate learning that is both authentic and explicit. They create environments which in Gardner's words enable students "naturally to link their intuitive ways of knowing with scholastic and disciplinary forms of knowing," and they build the capacity of learners to "take risks for understanding" (1991, p. 258).

Schools as museums, teachers as master craftsmen, and students as apprentice investigators - these are the educational environmental constructs in the high-stakes learning environment that we must create for our gifted students. They are asking us to rethink and transform the paradigm of traditional gifted education that says that more is better, faster is better, and more and faster are better yet. Content acceleration is a means to enhance learning environments for gifted children, but so are content enrichment, sophistication, and novelty.

Recently, one of our graduates returned to the Academy and we asked her, "How did IMSA prepare you for college?" Her answer was most disturbing: "IMSA did not prepare me for college. IMSA prepared me for graduate school. In college you are taught to memorize, memorize, memorize...I am waiting to get to graduate school so that I can think again." As educators interested in and committed to the education of gifted students, we must ensure that the environments that we create in elementary and secondary schools are sustained in higher education. College environments must also become intellectual learning communities for gifted youngsters, and that will require a transformation of the collegiate program as well as the elementary and secondary program.

As advocates of gifted children and gifted education, we are, in many ways, the guardians of our nation's future because the fate of humanity is, in no small means, in the hands of the children we teach.

\section{References}

Bloom, B. (Ed.), (1985) Developing Talent in Young People. New York, Ballantine Books.

Brown, R. (1991) Schools of Thought: How the Politics of Literacy Shape Thinking in the Classroom, San Francisco: Jossey-Bass. 
Gardner, H. (1991) The Unschooled Mind: How Children Think and How Schools Should Teach, New York, Basic Books.

Marland, S. (1972) Report to the Congress of the United States by the U. S. Commissioner of Education, Washington, DC; U. S. Government Printing Office.

Singal D, H, (1991, November), The Other Crisis in American Education, Atlantic Monthly, p. 59. 